\title{
Newcastle disease virus Malaysian strain AF2240 induces apoptosis in MCF-7 human breast carcinoma cells at an early stage of the virus life cycle
}

\author{
MOHAMED GHRICI $^{1}$, MOHAMED EL ZOWALATY ${ }^{3}$, ABDUL RAHMAN OMAR $^{1,3}$ and AINI IDERIS ${ }^{2,3}$
}

\begin{abstract}
Departments of ${ }^{1}$ Veterinary Pathology and Microbiology, ${ }^{2}$ Veterinary Clinical Studies, Faculty of Veterinary Medicine, Universiti Putra Malaysia; ${ }^{3}$ Laboratory of Vaccines and Immunotherapeutics, Institute of Bioscience, Universiti Putra Malaysia, 43400 UPM Serdang, Selangor Darul Ehsan, Malaysia
\end{abstract}

Received September 8, 2012; Accepted November 9, 2012

DOI: 10.3892/ijmm.2013.1244

\begin{abstract}
Newcastle disease virus (NDV) AF2240 Malaysian strain is a very virulent avian virus. NDV strain AF2240 was previously demonstrated to induce apoptosis in human breast carcinoma MCF-7 cells. However, at which stage of the NDV life cycle apoptosis is induced and whether NDV replication and protein synthesis are involved in apoptosis induction have yet to be determined. In the present study, we investigated the time course of NDV strain AF2240 nucleoprotein (NP) gene expression and the early apoptotic signs in the form of activation of caspase- 8 and mitochondrial transition pore opening. In addition, the induction of apoptosis by both ultravioletinactivated and cycloheximide-treated NDV-infected MCF-7 cells were examined. Our findings showed that NDV strain AF2240 induced apoptosis at $1 \mathrm{~h}$ post-infection (pi) through activation of mitochondrial transition pore opening and at $2 \mathrm{~h}$ through activation of caspase- 8 , while the NP gene was expressed at $6 \mathrm{~h}$ pi. The induced apoptosis was independent of both virus replication and protein synthesis. In conclusion, NDV strain AF2240 induces apoptosis at an early stage of its life cycle, possibly during virus binding or fusion with the cell membrane. The mitochondrial-related pathway may be the central activator in NDV strain AF2240-induced apoptosis.
\end{abstract}

Correspondence to: Aini Ideris, Department of Veterinary Clinical Studies, Faculty of Veterinary Medicine, Universiti Putra Malaysia, 43400 UPM Serdang, Selangor Darul Ehsan, Malaysia

E-mail: tnca@upm.my

Abbreviations: FADD, Fas-associated death domain; HAU, hemagglutination unit; $\mathrm{HN}$, hemagglutinin-neuraminidase; IFN- $\alpha$, interferon- $\alpha$; MCF-7, Michigan Cancer Foundation-7 human breast adenocarcinoma cell lines; NDV, Newcastle disease virus; NP, nucleoprotein; OIE, Organization for Animal Health; pi, post-infection; RT-PCR, reverse transcription-polymerase chain reaction; TNF, tumor necrosis factor; TRAIL, TNF-related apoptosis-inducing ligand

Key words: Newcastle disease virus AF2240, MCF-7 cells, apoptosis, caspase-8, mitochondria

\section{Introduction}

Newcastle disease virus (NDV), also known as avian paramyxovirus serotype-1 (APMV-1), belongs to the genus Avulavirus of the family Paramyxoviridae, subfamily Paramyxovirinae in the order of Mononegavirales (1). NDV is an enveloped, single-stranded, negative sense, and non-segmented RNA virus (2). The viral RNA encodes for six structural and two nonstructural proteins $(3,4)$. NDV causes fatal infections in over 250 species of birds, both domestic and wild. On the basis of pathogenicity, strains of NDV are categorized into three main pathotypes known as lentogenic (low virulence), mesogenic (medium virulence), and velogenic (high virulence) $(2,5,6)$.

NDV is notorious for its devastating effect on poultry that can cause $100 \%$ morbidity and mortality in chicken flocks, leading to a serious economic impact on the worldwide poultry industry (7). Therefore, velogenic NDV strains are included on the reportable contagious disease list A of the World Organization for Animal Health (OIE) (5,7). Furthermore, certain NDV strains are well-recognized among other viruses including adenovirus, rabies virus, poliovirus, herpes simplex virus, hepatitis A virus, influenza A virus, and measles virus for their antineoplastic and oncolytic effect on tumor cells, paving the way to a promising field in cancer virotherapy (8-10). Such NDV strains induce apoptosis in various cell types including chicken lymphocytes and various human tumor cells $(11,12)$.

Apoptosis is an active programmed physiologic process triggered in response to specific stimuli (13). Apoptosis is a multi-step and multi-pathway cell death program (14). In general, apoptosis can be triggered by two basic, nonexclusive pathways, a death receptor (extrinsic) pathway and a mitochondrial (intrinsic) pathway. Both pathways are interconnected and converge downstream of the apoptotic reaction cascade mainly at the execution level by activation of caspases which leads to the observed morphological and biochemical apoptotic features (14). The death receptor mediated pathway involves death receptors at cell surface such as the members of the tumor necrosis factor (TNF) family which directly activate upstream caspases such as caspase-8, an initiator caspase (15-17). The mitochondrial mediated pathway triggered by the perturbation of the mitochondrial membrane potential leads 
to the release of cytochrome $c$ and other apoptosis inducer molecules in the cytosol (18). In most apoptosis cases, the involvement of mitochondrial disruption precedes caspase activation (19).

NDV is recognized as an oncolytic virus that selectively replicates in tumor cells and kills them (20). Consequently, NDV has been used for decades in clinical settings (21-23). However, the molecular mechanism of NDV oncolysis is not fully understood. It was suggested that NDV oncolysis may be due to the major mitogen activated protein kinase pathway or due to a mechanism regulated by reactive oxygen species (24). In another study, TNF-related apoptosis-inducing ligand (TRAIL) was suggested to be the cause of NDV oncolysis (25). NDV-induced apoptosis was thus responsible for NDV oncolysis. Both death receptor and mitochondrial apoptotic pathways were triggered by NDV-induced apoptosis (26).

Recently, infections caused by NDV strain AF2240 were shown to induce conformational changes of Bax protein which in turn was translocated from the cytoplasm to mitochondria leading to the release of cytochrome $c$ in the cytoplasm (27). However, neither the signaling mechanism leading to conformational changes of Bax nor the type of apoptotic stimuli responsible for this were identified. In addition, the direct involvement of NDV gene(s) and the stage of the NDV life cycle at which apoptosis was induced were not investigated. The current study was thus conducted to determine at which stage of the NDV life cycle apoptosis was induced by comparing the time course of NDV nucleoprotein (NP) gene expression via reverse transcription-polymerase chain reaction (RT-PCR) amplification with the time course of apoptosis detection by caspase- 8 activation assay and mitochondrial transition pore assay.

\section{Materials and methods}

Cells and virus. Human breast carcinoma MCF-7 cell line (ATCC ${ }^{\circledR}$ number HTB-22 ${ }^{\mathrm{TM}}$ ) was cultured in RPMI-1640 medium supplemented with $10 \%$ fetal bovine serum and $1 \%$ antibiotic-antimycotic solution (Gibco-Invitrogen, Grand Island, NY, USA). Cultured cells were incubated at $37^{\circ} \mathrm{C}$ in a humidified atmosphere in the presence of $5 \% \mathrm{CO}_{2}$. Highly virulent Malaysian strain of NDV, known as AF2240, was used in the current study. Viral stocks were prepared by inoculation into 9-day-old specific pathogen-free (SPF) embryonated chicken eggs by the allantoic route according to the European Community directive 92/66/EC (28). After four days of incubation, the eggs were chilled at $4^{\circ} \mathrm{C}$ for $24 \mathrm{~h}$, the allantoic fluids were aseptically harvested, and tested for hemagglutination activity using chicken erythrocytes $[0.5 \%$ in $0.01 \mathrm{M}$ phosphatebuffered saline (PBS), pH 7.2]. The infected allantoic fluids were purified as previously described (29). The virus was titrated by hemagglutination activity assay and stored at $-80^{\circ} \mathrm{C}$ for later use.

\section{Time course of NDV NP gene expression}

Total RNA extraction. RNA was extracted from infected allantoic fluid of NDV strain AF2240 using TRI-reagent according to the manufacturer's instructions (Promega Corporation, Madison, WI, USA) and it was used as a positive control for NP detection. The time course study of NP gene expression was performed on total RNA isolated at various time intervals of $0,3,6,9,12$ and $24 \mathrm{~h}$ post-infection (pi) from MCF-7 cells infected with 250 hemagglutination units (HAUs) of NDV strain AF2240 using the SV total RNA isolation system according to the manufacturer's instructions (Promega Corporation). The RNA pellet was re-suspended in $20 \mu \mathrm{l}$ nuclease-free water (Promega Corporation) after being air dried for immediate use or kept in $-80^{\circ} \mathrm{C}$ for later use.

RT-PCR amplification of the NP gene. The NP gene was amplified by RT-PCR using a set of primers designed based on the published sequence of NDV strain AF2240 (accession no. AF284646) using the primer premier 5.0 TM software. The primer set sequences were: forward, 5'-GGTATTCTGTCTTCGGATTG-3' and reverse, 5'-TCA TCCGATAATAAACGCAT-3'. The amplification of the $754 \mathrm{bp}$ NP gene was carried out using Access RT-PCR system (Promega Corporation). The first cDNA synthesis was performed in a reaction volume containing $5 \mu \mathrm{l}$ of $5 \mathrm{X}$ reaction buffer, $3 \mathrm{mM}$ $\mathrm{MgCl}_{2}, 200 \mathrm{mM}$ each of dNTP mix, $10 \mathrm{pmol}$ of each primer, $1 \mu \mathrm{l}$ of RNasin plus RNase inhibitor, and 10 units AMV reverse transcriptase enzyme. Nuclease free water was added to a final volume of $25 \mu \mathrm{l}$. Total RNA extracted at various time intervals was added at concentration of $1 \mu \mathrm{g}$ to the reaction mixture and incubated at $42^{\circ} \mathrm{C}$ for $45 \mathrm{~min}$ followed by one step of $98^{\circ} \mathrm{C}$ for $5 \mathrm{~min}$.

PCR amplification of the NP gene was performed by adding $2.5 \mu \mathrm{l}$ of the reverse transcription mixture to PCR reaction mixture containing $2.5 \mu \mathrm{l}$ of $10 \mathrm{X}$ reaction buffer, $3 \mathrm{mM}$ $\mathrm{MgCl}_{2}, 200 \mathrm{mM}$ each of dNTP mix, 10 pmol of each primer, 5 units of Taq DNA polymerase, and nuclease free water to make a final volume of $25 \mu \mathrm{l}$. The cycling parameters were $94^{\circ} \mathrm{C}$ for $2 \mathrm{~min}$ followed by 40 cycles of $95^{\circ} \mathrm{C}$ for $30 \mathrm{sec}, 55^{\circ} \mathrm{C}$ for $50 \mathrm{sec}, 72^{\circ} \mathrm{C}$ for $1 \mathrm{~min}$, and a final step of $69^{\circ} \mathrm{C}$ for $10 \mathrm{~min}$. PCR products were separated by $1.5 \%$ agarose gel electrophoresis and visualized under ultraviolet (UV) light after being stained with ethidium bromide.

Ultraviolet light inactivation. Five hundred HAUs of NDV strain AF2240 were exposed to various concentrations of UV light power ranging from 2, 5, 10, 50, 100 and $200 \mathrm{~mW} / \mathrm{cm}^{2}$ for various time intervals of $5,10,15$ and $30 \mathrm{~min}$ at $5 \mathrm{~cm}$ distance from the UV lamp (254 nm). The complete inactivation of NDV was assessed by inoculation in duplicate of UV-treated NDV into allantoic fluid of embryonated SPF eggs and incubated for 7 days at $37^{\circ} \mathrm{C}$. The complete inactivation was confirmed by plaque forming assay.

Cycloheximide treatment. Non-infected and NDV AF2240 infected MCF-7 cell monolayers were treated with $100 \mu \mathrm{g} / \mathrm{ml}$ of cycloheximide (CHX) $1 \mathrm{~h}$ after infection with $250 \mathrm{HAUs}$ of NDV AF2240 at $37^{\circ} \mathrm{C}$ in a $5 \% \mathrm{CO}_{2}$ atmosphere. Following the removal of $\mathrm{CHX}$, the treated cells were incubated for 24 and $48 \mathrm{~h}$ pi at $37^{\circ} \mathrm{C}$ in a $5 \% \mathrm{CO}_{2}$ atmosphere. The cells were collected and processed for apoptosis detection according to a previous method, with modifications (30).

\section{Flow cytometry}

Detection of $U V$-inactivated NDV strain AF2240 induction of apoptosis. Five hundred HAUs of NDV exposed to UV power of $50 \mathrm{~mW} / \mathrm{cm}^{2}$ for $5 \mathrm{~min}$ at a $5 \mathrm{~cm}$ distance from the UV lamp were used to infect MCF-7 cells. After $1 \mathrm{~h}$ adsorption, the virus inoculums were removed and fresh RPMI-1640 


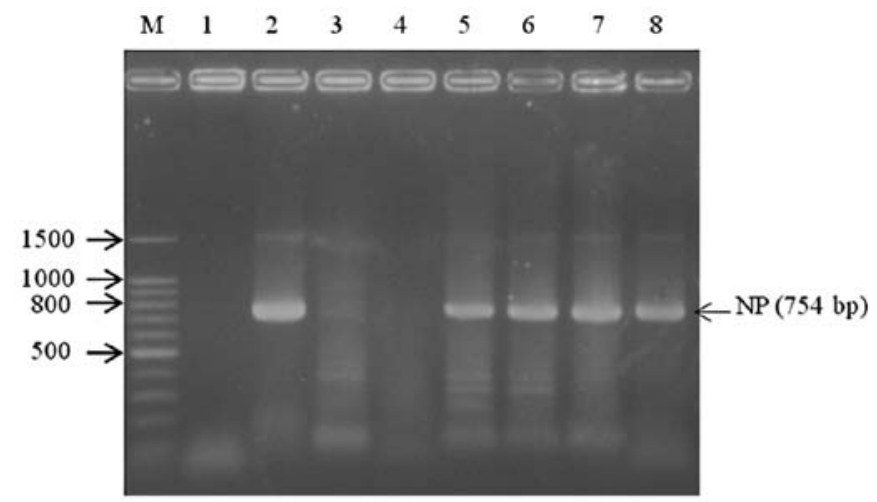

Figure 1. Amplification of the NP gene using RT-PCR: agarose gel electrophoresis of RT-PCR amplified products of total RNA extracted from NDV-infected MCF-7 cells at various time intervals. (Lane M) Represents DNA molecular size marker (Promega Corporation). (Lanes 1 and 3) Represent negative control of non-infected MCF-7 cells. (Lane 2) Represents positive control of NP transcript amplified from RNA extracted from NDV-inoculated SPF embryonated eggs. (Lane 4) The amplified NP transcript with the size of 754 bp was not detected at $3 \mathrm{~h}$ pi, however it was detected at $6 \mathrm{~h}$ pi (lane 5), at $9 \mathrm{~h}$ pi $12 \mathrm{~h}$ pi (lanes 6 and 7), and at $24 \mathrm{~h}$ pi (lane 8 ). Numbers on the left indicate the molecular weights (bp) of the DNA marker. Arrowed number on the right indicates DNA band size of the NP gene.

medium was added. The infected cells were incubated for $48 \mathrm{~h}$ at $37^{\circ} \mathrm{C}$ in a $5 \% \mathrm{CO}_{2}$ atmosphere. The induced apoptosis was assessed by flow cytometry according to a previously described method, with modifications (30). In brief, cells were processed by successive centrifugation at $1,000 \mathrm{rpm}$ for $10 \mathrm{~min}$ followed by fixation in $80 \%$ cold ethanol for $2 \mathrm{~h}$ at $4^{\circ} \mathrm{C}$. After 3 successive centrifugations at $1,000 \mathrm{rpm}$ for $10 \mathrm{~min}$, the cells were incubated for $5 \mathrm{~min}$ at $4^{\circ} \mathrm{C}$ in PBS buffer containing $10 \mathrm{mM}$ Triton X-100 and $50 \mathrm{mg} / \mathrm{ml}$ of RNase A. The cells were collected by centrifugation at $1,000 \mathrm{rpm}$ for $10 \mathrm{~min}$ and incubated for $30 \mathrm{~min}$ at $4^{\circ} \mathrm{C}$ in $1 \mathrm{ml}$ PBS buffer containing $5 \mu \mathrm{g} / \mathrm{ml}$ of propidium iodide. The stained cells were then analyzed with CyAn ADP, Beckman Coulter flow cytometer. The data were analyzed with Summit v4.3 software (Beckman Coulter, Brea, CA, USA).

Detection of NDV AF2240-induced apoptosis in CHX-treated MCF-7 cells. NDV-infected MCF-7 cells were infected and treated with $\mathrm{CHX}$ as described above. At each time interval, the cells were processed for flow cytometry according to a previously described method, with modifications (30).

Caspase- 8 assay. The apoptosis induced in UV-inactivated NDV AF2240 infected MCF-7 cells was detected via caspase-8 activation assay. In brief, MCF-7 cells $\left(10^{5}\right)$ grown on chamber slides were infected either with 500 HAUs of UV-treated NDV AF2240 or with CHX treated MCF-7 cells infected with 250 HAUs NDV AF2240 strain. After $1 \mathrm{~h}$ adsorption, the inocula were discarded and caspase- 8 activation was assessed at various time intervals of 1, 2, 3, 6, 9 and $12 \mathrm{~h}$ pi. After each time interval, the cells were processed for caspase- 8 activation detection according to the manufacturer's protocol (Molecular Probes, Invitrogen, Grand Island, NY, USA).

Mitochondrial transition pore assay. MCF-7 cell monolayers grown on chamber slides were infected with 250 HAUs of NDV strain AF2240 as described above. The infected cells were incubated at $37^{\circ} \mathrm{C}$ in a $5 \% \mathrm{CO}_{2}$ atmosphere for various
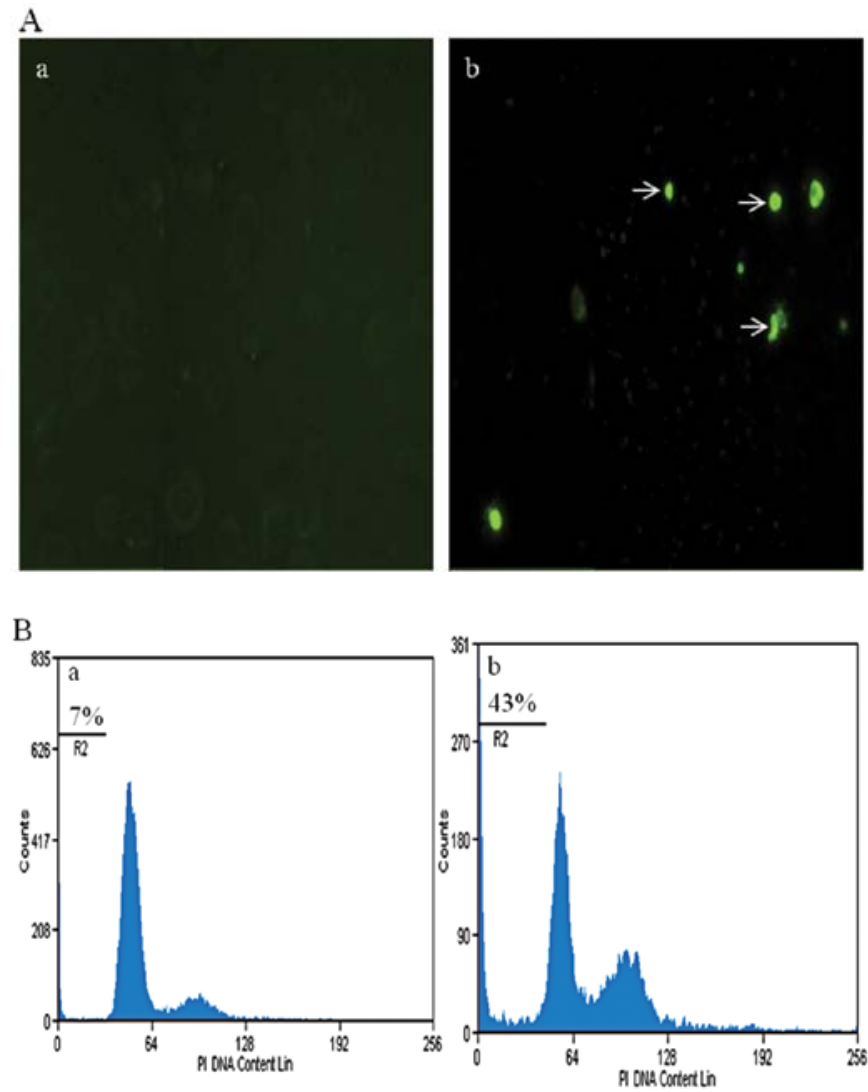

Figure 2. (A) Apoptosis detection: apoptosis was detected via caspase- 8 activation of NDV strain AF2240-induced apoptosis in MCF-7 cells. (Aa) Represents non-infected MCF-7 cells. (Ab) Represents caspase-8 activation in MCF-7 cells infected with 250 HAUs of NDV strain AF2240 as detected at $2 \mathrm{~h}$ pi. (B) Flow cytometry: analysis of NDV strain AF2240induced apoptosis in MCF-7 cells infected with 50 HAUs of virus. Marker R2 represents the percentage of apoptotic cells in NDV strain AF2240 in noninfected $(\mathrm{Ba})$ and infected $(\mathrm{Bb}) \mathrm{MCF}-7$ cells. The counts refer to the number of events. Data are representative of three independent experiments.

time intervals of $30 \mathrm{~min}, 1,2,3,6,9$ and $12 \mathrm{~h}$ pi. At the end of each time interval, the non-infected and infected MCF-7 cells were processed for detection of the activation of mitochondrial transition pore opening using Image-iT ${ }^{\circledR}$ LIVE Mitochondrial transition pore assay kit, according to the manufacturer's protocol (Molecular Probes, Invitrogen).

\section{Results}

The comparison of the time course detection of the first NDV gene expressed with the time course detection of the early sign of apoptosis was used to identify the stage of the NDV life cycle at which apoptosis was induced. The early NDV gene expression was carried out using RT-PCR amplification of the NP gene. The experiment was repeated in triplicate. The NP transcript with the size of 754 bp could not be detected before $6 \mathrm{~h}$ pi, however, it was amplified after $6 \mathrm{~h}$ pi, and at 9, 12 and 24 h pi (Fig. 1).

The first early sign of apoptosis used as caspase- 8 activation was detected at $2 \mathrm{~h}$ pi (Fig. 2A). Apoptosis induced by the NDV strain AF2240 was further confirmed by flow cytometry analysis (Fig. 2B). To exclude that NDV replication is not involved in apoptosis induction, $500 \mathrm{HAUs}$ of NDV strain AF2240 were inactivated by exposure to various concentra- 
Table I. Ultraviolet inactivation of NDV Malaysian strain AF2240.

\begin{tabular}{ccccc}
\hline \multirow{2}{*}{$\begin{array}{l}\text { UV power } \\
\left(\mathrm{mW} / \mathrm{cm}^{2}\right)\end{array}$} & \multicolumn{5}{c}{ Time of exposure of NDV AF2240 } & $(\mathrm{min})$ \\
\cline { 2 - 5 } & 5 & 10 & 15 & 30 \\
\hline 2 & + & + & + & + \\
5 & + & + & + & + \\
10 & + & + & + & + \\
50 & - & - & - & - \\
100 & - & - & - & -
\end{tabular}

Exposure of 500 HAUs of NDV strain AF2240 to different concentrations of UV power at different time intervals. Each virus aliquot was inoculated into 5 specific pathogen-free (SPF) eggs and incubated for 5 days at $37^{\circ} \mathrm{C}$. At the end of the incubation period, inoculated eggs were candled and designated as $(+)$ which represented live and (-) which represented dead SPF eggs. Eggs inoculated with 25 HAUs of NDV AF2240 were killed at 3 days post-infection (pi) (data not shown). The virus inoculation was performed in triplicates.
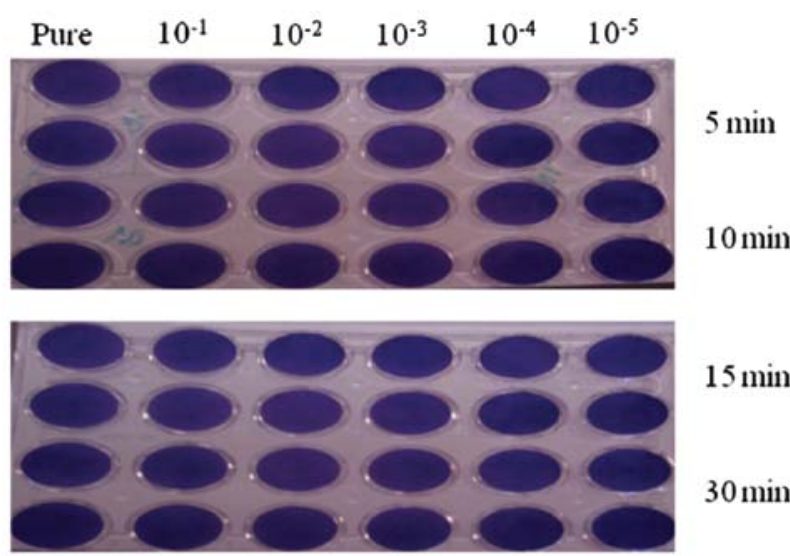

$15 \mathrm{~min}$

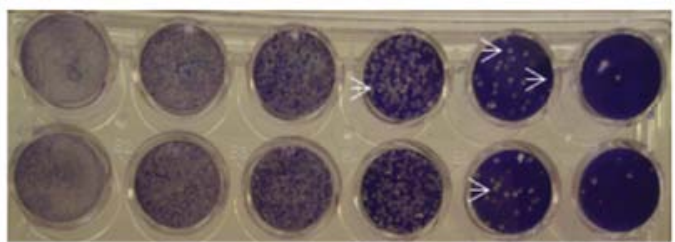

$30 \mathrm{~min}$

$25 \mathrm{HAU}$

Figure 3. Infectivity of UV-inactivated NDV strain AF2240 and NDV strain AF2240. Five hundred HAUs of virus were exposed to UV light power of $50 \mathrm{~mW} / \mathrm{cm}^{2}$ for $5,10,15$ and $30 \mathrm{~min}$ at a $5 \mathrm{~cm}$ distance from the UV light source. The infectivity of the UV-inactivated NDV strain AF2240 was assessed in Vero cells by plaque forming assay at 4 days pi. NDV strain AF2240 was completely inactivated following exposure to UV light for various time intervals of 5, 10, 15 and 30 min while 25 HAUs was fully infective even at very low titer of $10^{-4}$ (arrows).

tions of UV light power for various time intervals. NDV strain AF2240 was completely inactivated at UV light power of $50 \mathrm{~mW} / \mathrm{cm}^{2}$ for $5 \mathrm{~min}$. The complete inactivation was assessed by inoculation of UV-treated NDV into SPF eggs and showed that the SPF embryonated eggs were still alive after 5 days of incubation while all SPF eggs inoculated with 25 HAUs died after 3 days of inoculation (Table I). In addition, the complete UV inactivation of NDV strain AF2240 was confirmed by
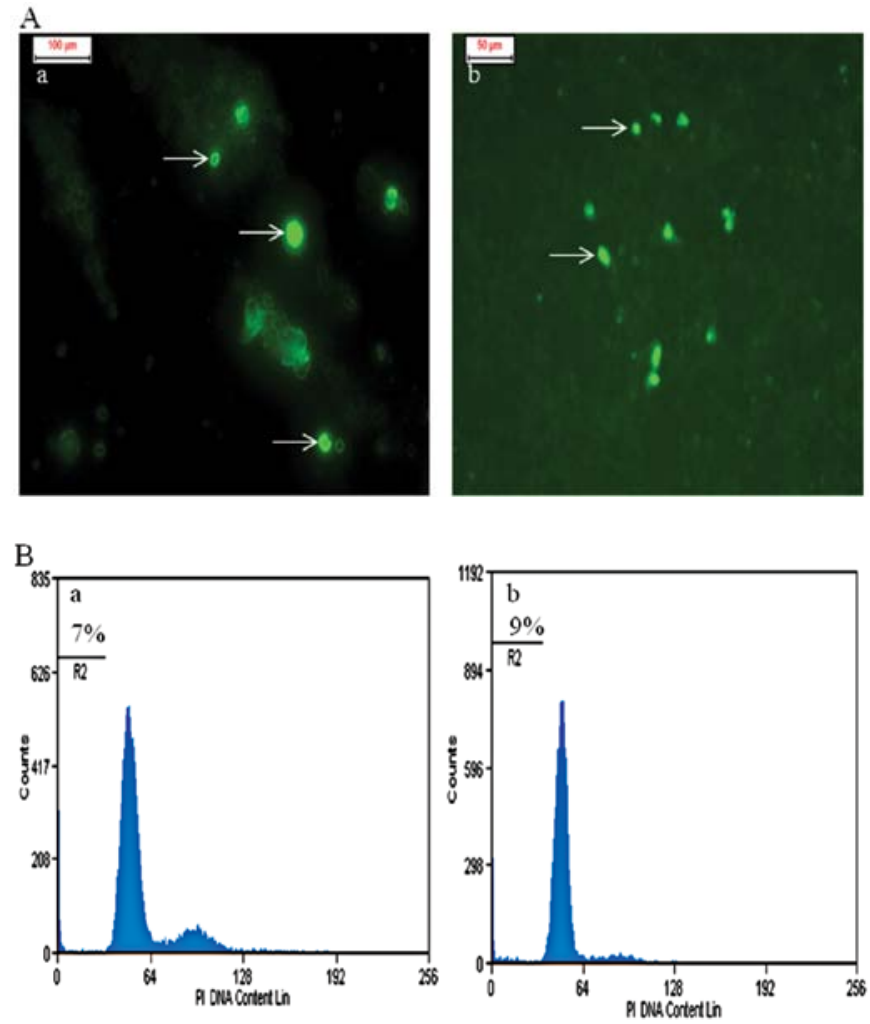

Figure 4. UV-inactivated NDV strain AF2240-induced apoptosis (A) Apoptosis detection: apoptosis was detected at $2 \mathrm{~h}$ pi via caspase- 8 activation induced by UV inactivation of 500 HAUs of NDV strain AF2240 which was previously exposed to UV power of $50 \mathrm{~mW} / \mathrm{cm}^{2}$ at a distance of $5 \mathrm{~cm}$ from the UV lamp for 5 (Aa) and $30 \mathrm{~min}(\mathrm{Ab})$. (B) Flow cytometry: MCF-7 cells infected with 500 HAUs of UV-inactivated NDV strain AF2240 were incubated for $48 \mathrm{~h}$ at $37^{\circ} \mathrm{C}$ in a humidified atmosphere of $5 \% \mathrm{CO}_{2}$. The apoptosis induced in non-infected (Ba) and infected (Bb) MCF-7 cells was analyzed by flow cytometry. Marker R2 represents the percentage of apoptotic cells and the counts refer to the number of events. Data are representative of three independent experiments.

plaque forming assay. There were no plaques formed in Vero cells infected with 500 HAUs of UV-treated NDV strain AF2240 exposed to $50 \mathrm{~mW} / \mathrm{cm}^{2}$ at any time interval while 25 HAUs NDV strain AF2240 generated 7x $10^{5}$ pfu (Fig. 3). UV inactivation of NDV strain AF2240 for 5 min generated more apoptotic cells than exposure for $30 \mathrm{~min}$ with the same UV power of $50 \mathrm{~mW} / \mathrm{cm}^{2}$ (Fig. 4A). Furthermore, we determined whether UV-treated NDV strain AF2240 was able to induce apoptosis in MCF-7 cells. UV-treated NDV strain AF2240 induced apoptosis in MCF-7 cells, although at a very low level at $48 \mathrm{~h}$ pi (Fig. 4B).

To determine whether NDV protein synthesis was involved in NDV-induced apoptosis, MCF-7 cells were treated with $100 \mu \mathrm{g} / \mathrm{ml}$ of CHX for $1 \mathrm{~h}$ after infection of the cells with 250 HAUs of NDV. The induction of apoptosis was confirmed by the detection of caspase- 8 activation in the treated and infected MCF-7 cells (Fig. 5A). It was found that apoptosis was induced in the treated and infected MCF-7 cells and it was absent in the treated non-infected MCF-7 cells as shown by flow cytometry analysis in Fig. 5B.

NDV-induced apoptosis may be mediated by either the death receptor pathway alone or by both the death receptor and the mitochondrial associated pathways. The detection of caspase- 8 activation induced by NDV strain AF2240, as 

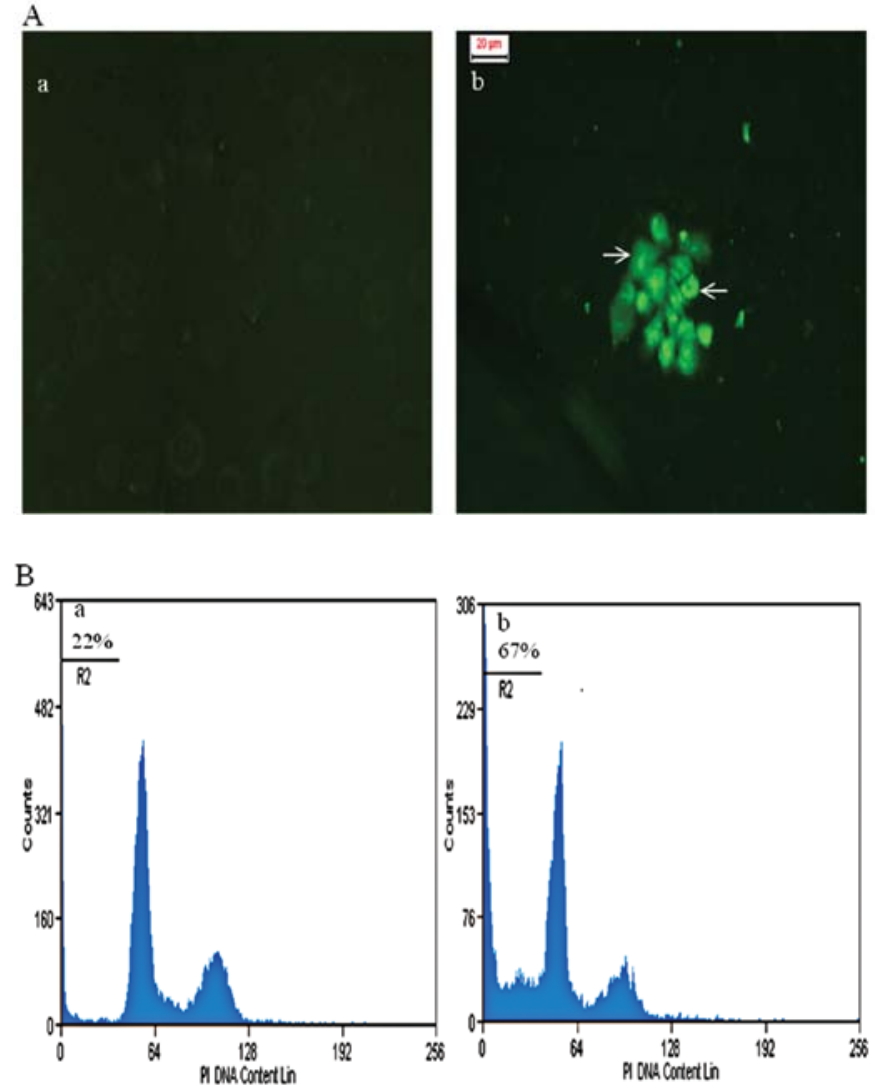

Figure 5. NDV strain AF2240-induced apoptosis in CHX-treated MCF-7 cells. MCF-7 cells were treated with $100 \mu \mathrm{g} / \mathrm{ml}$ of $\mathrm{CHX}$ for $1 \mathrm{~h}$ after infection with 250 HAUs NDV strain AF2240. (A) Apoptosis detection: apoptosis was detected via caspase- 8 activation at $2 \mathrm{~h}$ pi $(\mathrm{Ab})$ compared to non-infected MCF-7 cells (Aa). (B) Flow cytometry: detection of apoptosis by flow cytometry at $48 \mathrm{~h}$ pi. Both treated non-infected $(\mathrm{Ba})$ and treated infected $(\mathrm{Bb})$ MCF-7 cells were analyzed. The bar in each graph represents the sub- $\mathrm{G}_{0}-\mathrm{G}_{1}$ population of cells containing hypoploid DNA (indicated as percentage) and was considered apoptotic. Data are representative of three independent experiments.

shown earlier, may be related to either the death receptor pathway or to an alternative pathway. However, the involvement of the mitochondrial associated pathway in NDV strain AF2240-induced apoptosis was demonstrated through the detection of mitochondrial transition pore opening activation. This was detected at $1 \mathrm{~h}$ pi before caspase- 8 activation detection (Fig. 6).

\section{Discussion}

The main objective of the present study was to determine the stage of the NDV life cycle at which apoptosis was induced. Our aim was to identify the NDV gene responsible for apoptosis induction. This gene may be used either alone or in association with other therapeutic genes to enhance NDV tumor cell killing. For this purpose, we compared two time course kinetics. First, we investigated the time course of NDV gene expression by RT-PCR amplification of NP gene transcript. The NP gene is the first ORF to be transcribed and is more abundant than any other NDV gene (31). Second, we investigated the time course detection of early signs of apoptosis in the form of activation of caspase- 8 and mitochondrial transition pore opening. NDV gene expression started at $6 \mathrm{~h}$ pi
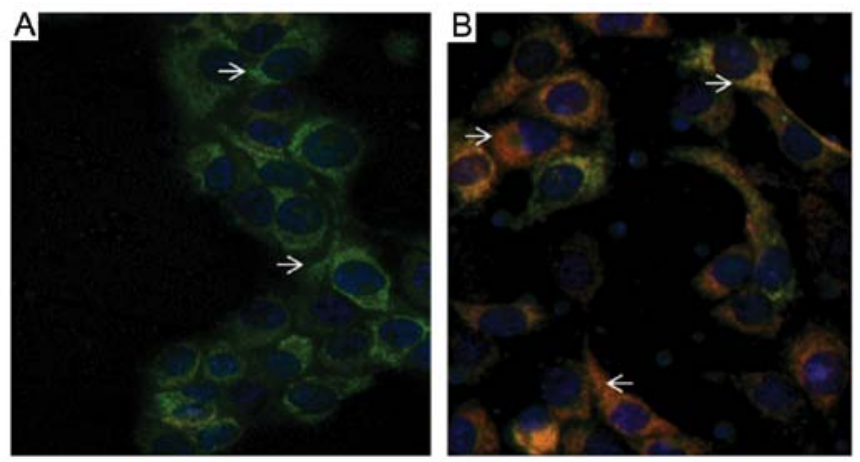

Figure 6. Detection of mitochondrial permeability transition pore opening activation. MCF-7 cells were infected with $250 \mathrm{HAUs}$ of NDV strain AF2240 and incubated for $1 \mathrm{~h}$ pi at $37^{\circ} \mathrm{C}$ in a humidified atmosphere of $5 \% \mathrm{CO}_{2}$. The mock-infected and infected cells were labelled then incubated for $15 \mathrm{~min}$ at $37^{\circ} \mathrm{C}$ in a $5 \% \mathrm{CO}_{2}$ incubator and washed twice with modified HBSS buffer. The green mitochondrial calcein fluorescence was maintained in mockinfected cells in the form of comet (arrows) (A), while it was lost in the NDV strain AF2240 infected cells (B). The nucleus was stained blue with Hoechst. The infected MCF-7 cells displayed red and yellow fluorescence (arrows), a typical feature of the mitochondrial permeability transition pore opening.

and its detection was in accordance with a previous report in which overall, transcription of NDV genes starts after $5 \mathrm{~h}$ pi (32). However, the time course of NDV gene expression may vary depending on the virulence of the NDV strain and on the cell type used, in addition to the differences of laboratory conditions in which these different investigations were carried out.

Our early detection of apoptosis at $2 \mathrm{~h}$ pi in the form of caspase- 8 activation was in contrast to previous studies in which caspase- 8 activation was detected at $48 \mathrm{~h}$ pi using Apo Alert caspase fluorescent assay (26). In another study, caspase- 8 activation was detected at $24 \mathrm{~h}$ pi (33). These differences in the detection time of caspase- 8 activation may be related to virus strain virulence. In this study, we used a highly virulent NDV strain AF2240 while the reported studies used avirulent and non-lytic strains to moderate pathogenic strains of NDV (26,33). Other factors such as the cell type system, the laboratory conditions and assays used to detect apoptosis may have contributed to these time differences. Alternatively, the time differences of caspase- 8 activation may be due to activation of caspase- 8 through different apoptotic pathways induced by NDV strains of different virulence. In addition, other proapoptotic molecules may activate caspase- 8 independently of the death receptor pathway. However, this hypothesis requires further investigation.

Although the results of the UV-NDV experiment appeared to be in accordance with previous reports (34), our detection of apoptosis at $1 \mathrm{~h}$ pi is much earlier than any NDV strain AF2240 gene expression. This strongly suggests that NDV strain AF2240 replication was not necessary for apoptosis induction as opposed to a previous report (34) and that the virus binding to MCF-7 cell surface receptor may be sufficient to induce apoptosis. Consequently, apoptosis was induced much earlier than NDV transcription and replication. The theory that apoptosis may be virus replication-independent was confirmed by inhibition studies in which virus replication was inhibited by UV inactivation. However, the level of apoptosis induced by UV inactivated NDV strain AF2240 was 
much lower than that of apoptosis induced by non-inactivated NDV strain AF2240. This can be partially explained by the UV power used which may be deleterious to the biological function of the attachment hemagglutinin-neuraminidase (HN) protein or to the cytosolic proteins including caspases. Previous studies demonstrated a less efficient binding and/or fusion activity due to the deleterious effect of UV irradiation on viral proteins as well as on viral RNA (35).

NDV was shown to be heat sensitive (36) and thus prolonged UV treatment for $30 \mathrm{~min}$ as shown in our study which induced less apoptotic cells than 5 min exposure. In addition, higher UV power generates heat which can destroy most of NDV potency to induce interferon (IFN)- $\alpha$ and TRAIL (37) or to destroy the virus cell binding capacity probably by protein denaturation. Another explanation is that the low level of apoptosis induced by UV inactivated NDV strain AF2240 may also be due to insufficient particle threshold required for high levels of apoptosis induction as previously reported (35). UV inactivation of NDV strain AF2240 may require a large amount of virus particle to induce sufficient apoptosis levels as demonstrated with UV inactivated reovirus which required 100-fold greater virus particles than wild-type to induce stronger apoptosis levels (35).

The purpose of UV inactivation of NDV strain AF2240 was to destroy the virus ability to infect MCF-7 cells while preserving its ability to bind to cell surface receptor. However, this objective seemed to be missed in our study compared to previous studies in which UV inactivated viruses including reovirus (35), Sindbis virus (38), vaccinia virus (39), and African swine fever virus (40) were able to induce apoptosis. All these viruses induced an early apoptosis independently of their replication and protein synthesis.

The induction of apoptosis at the early stage of the viral life cycle may suggest that the attachment protein $\mathrm{HN}$ and its cellular receptor were involved in apoptosis induction as it has been suggested for other viruses such as the reovirus attachment protein $\sigma 1$ (35) and the cellular receptor in vaccinia virus (39). NDV-induced apoptosis may require virus binding to the cell surface receptor. This may explain why short exposure of 30 min of the attenuated NDV MTH-68/H vaccine strain to PC 12 cells induced full blown apoptosis (24). In fact, a shorter exposure of $10 \mathrm{~min}$ may be sufficient to induce apoptosis since the attachment of NDV to target cells is very rapid and is complete within 10 min of infection, as previously demonstrated (41).

NDV virulence may not have an advantage in apoptosis induction since several avirulent strains such as Ulster, LaSota and moderate strains such as Beaudette strain induced apoptosis (26). However, the virulence may influence the early apoptosis induction such as in our case of NDV strain AF2240 and in the case of NDV strain GB, a virulent strain which induced apoptosis in chicken peripheral blood lymphocyte at $3 \mathrm{~h}$ pi based on chromatin condensation (42). The virulence can be an important determinant of apoptosis as demonstrated previously in the Sindbis virus (38). However, the conclusive role of virulence in early apoptosis induction requires further investigation.

NDV strain AF2240 protein synthesis was unlikely involved in apoptosis induction. The treatment of NDV-infected MCF-7 cells with CHX did not inhibit NDV AF2240-induced apoptosis and hence the induced apoptosis may be protein synthesis-independent. Our results differed from a previous report in which CHX treatment inhibited NDV-induced apoptosis in Vero cells (34).

Generally, apoptosis can be mediated by the death receptor pathway and/or by the mitochondrial apoptotic pathway (14). NDV strain AF2240-induced apoptosis was mediated by both apoptotic pathways, and with the mitochondrial pathway as a central activator of NDV strain AF2240-induced apoptosis. This latter can be ascertained by blocking caspase- 8 activation by caspase- 8 inhibitor to determine whether apoptosis proceeds after the blocking of caspase- 8 activation. The opening of the permeability transition pores in mitochondria may be the first irreversible step common to all forms of apoptosis (43). However, it is not known whether the release of its inter-membrane molecules is the signal for the cells to 'commit suicide' (44). According to model of Green (14), caspase- 8 is activated following ligation of death receptor which recruits adaptor proteins such as Fas-associated death domain (FADD) which in turn recruit pro-caspase- 8 and these molecules by being close to each other, cleave its nearest neighbors into an active and mature caspase-8. Caspase- 8 is activated following TRAIL binding to its cell surface receptor $(37,45)$. Higher TRAIL expression was demonstrated previously in NDV-infected cells $(25,37,46)$. However, the involvement of TRAIL in NDV strain AF2240-induced apoptosis was not investigated and cannot be completely excluded until further evidence. In addition, the probability of involvement of other death ligands such as Fas ligand (CD95 ligand, FasL) and TNF- $\alpha$ may be low since only TRAIL expression was reported and it was responsible for NDV Ulster tumoricidal activity (25). However, TRAIL is unlikely to be the trigger of apoptosis in MCF-7 cells which was previously demonstrated to be resistant to TRAIL (25).

The involvement of the mitochondrial-related pathway in NDV strain AF2240-induced apoptosis was determined via the activation of mitochondrial permeability transition pore opening. This latter was detected at $1 \mathrm{~h}$ pi, much earlier than the reported disruption of mitochondrial membrane potential at $24 \mathrm{~h}$ pi (26). Our hypothesis that the mitochondrial pathway may be the central mechanism in NDV strain AF2240-induced apoptosis in MCF-7 cells was in agreement with previous reports that the mitochondrial pathway may be a predominant mechanism (46) or play a central role in NDV-induced apoptosis (26). However, the reported time of induction of mitochondrial pathway at $48 \mathrm{~h}$ pi (46) was much different from our results.

In addition, our hypothesis may be verified since NDV strain AF2240 infection was demonstrated to induce Bax conformational changes which in turn translocate into mitochondria and lead to cytochrome $c$ release (27). However, the detection time of apoptosis was different; while we detected the mitochondrial transition pore opening activation at $1 \mathrm{~h} \mathrm{pi}$, a previous study reported a detection of conformational changes of Bax and the cytochrome $c$ release between 6 and $32 \mathrm{~h}$ pi (27). The involvement of Bax in NDV-induced apoptosis was previously reported, although at a much later time, at $48 \mathrm{~h} \mathrm{pi}$ (33). This detection time divergence may highlight the possible existence of an earlier apoptotic stimulus different from Bax 
which was induced by NDV strain AF2240 infection. The search for the initial pro-apoptotic signal induced by NDV strain AF2240 was our main objective and we are currently performing further studies in order to elucidate this.

The cellular stress proteins which are stimulated by NDV infection (47) may induce or contribute to apoptosis by either inducing the expression of death ligand and subsequent apoptosis (48) and/or the stress-induced signals may be transduced to the mitochondria by action of one or more members of the BH3-only sub family of the pro-apoptotic Bcl-2 proteins (14).

In conclusion, NDV strain AF2240 induced apoptosis at the early stage of the NDV life cycle, independently of its replication and protein synthesis. This apoptosis may be mediated by both apoptotic pathways with the mitochondrial pathway playing the major role. We demonstrated that NDV strain AF2240 induced apoptosis at an early time, at $1 \mathrm{~h}$ pi. NDV replication was unlikely to be involved in apoptosis induction. The mitochondrial associated death pathway seems to be induced first, followed by caspase- 8 activation, suggesting that NDV-induced apoptosis in MCF-7 cells may be mediated by both pathways. Currently, we are conducting further investigations on the genetic manipulation of the NDV strain AF2240 for its use in cancer virotherapy, which will be clinically promising in the field of cancer treatment and control.

\section{Acknowledgements}

This study was supported by a grant from Malaysian National Cancer Council (MAKNA). We thank Mr. Rafiuz Zaman Haroun, the Microscopy Unit and Ms. Norsharina Ismail, the Laboratory of Molecular Biomedicine, Institute of Bioscience, UPM Serdang for their technical support in fluorescence and flow cytometry analysis. Dr Mohamed Ezzat El Zowalaty, Lecturer, Department of Microbiology and Immunology, Faculty of Pharmacy, Zagazig University, Zagazig, Egypt, is a postdoctoral research fellow under sponsorship of the Ministry of Higher Education, Malaysia.

\section{References}

1. Mayo M: A summary of taxonomic changes recently approved by ICTV. Arch Virol 147: 1655-1656, 2002.

2. Seal BS, King DJ and Sellers HS: The avian response to Newcastle disease virus. Dev Comp Immunol 24: 257-268, 2000.

3. De Leeuw O and Peeters B: Complete nucleotide sequence of Newcastle disease virus: evidence for the existence of a new genus within the subfamily Paramyxovirinae. J Gen Virol 80 131-136, 1999.

4. Krishnamurthy S and Samal SK: Nucleotide sequences of the trailer, nucleocapsid protein gene and intergenic regions of Newcastle disease virus strain Beaudette $\mathrm{C}$ and completion of the entire genome sequence. J Gen Virol 79: 2419-2424, 1998.

5. El Zowalaty ME, Chander Y, Redig PT, El Latif HKA, et al Selective isolation of avian influenza virus (AIV) from cloacal samples containing AIV and Newcastle disease virus. J Vet Diagn Invest 23: 330-332, 2011.

6. Hanson R and Brandly C: Identification of vaccine strains of Newcastle disease virus. Science 122: 156-157, 1955.

7. Alexander DJ: Newcastle disease, other avian paramyxoviruses, and pneumovirus infections. In: Diseases of Poultry. Saif JM Barnes HJ, Glisson JR, Fadly AM, McDougald LR and Swayne DE (eds). 11th edition. Iowa State University Press, Ames, Iowa, USA pp63-99, 2003.

8. Alabsi AM, Ali R, Ideris A, Omar AR, et al: Anti-leukemic activity of Newcastle disease virus strains AF2240 and V4-UPM in murine myelomonocytic leukemia in vivo. Leuk Res 36: 634-645, 2011
9. Lam HY, Yeap SK, Rasoli M, Omar AR, Yusoff K, Suraini AA and Alitheen NB: Safety and clinical usage of Newcastle disease virus in cancer therapy. J Biomed Biotechnol 2011: 718710, 2011 (Epub ahead of print).

10. Sinkovics JG and Horvath JC: Newcastle disease virus (NDV): Brief history of its oncolytic strains. J Clin Virol 16: 1-15, 2000.

11. Lam K, Vasconcelos A and Bickford A: Apoptosis as a cause of death in chicken embryos inoculated with Newcastle disease virus. Microb Pathog 19: 169-174, 1995

12. Washburn B and Schirrmacher V: Human tumor cell infection by Newcastle disease virus leads to upregulation of HLA and cell adhesion molecules and to induction of interferons, chemokines and finally apoptosis. Int J Oncol 21: 85-93, 2002.

13. Fawthrop DJ, Boobis AR and Davies DS: Mechanisms of cell death. Arch Toxicol 65: 437-444, 1991.

14. Green DR: Apoptotic pathways: paper wraps stone blunts scissors. Cell 102: 1-4,2000.

15. Budihardjo I, Oliver H, Lutter M, Luo X and Wang X: Biochemical pathways of caspase activation during apoptosis. Annu Rev Cell Dev Biol 15: 269-290, 1999.

16. Hengartner MO: The biochemistry of apoptosis. Nature 407: 770-776, 2000.

17. Igney FH and Krammer PH: Death and anti-death: tumour resistance to apoptosis. Nat Rev Cancer 2: 277-288, 2002.

18. Hu S, Vincenz C, Buller M and Dixit VM: A novel family of viral death effector domain-containing molecules that inhibit both CD-95-and tumor necrosis factor receptor-1-induced apoptosis. J Biol Chem 272: 9621-9624, 1997.

19. Zamzami N, Marchetti P, Castedo M, Zanin C, et al: Reduction in mitochondrial potential constitutes an early irreversible step of programmed lymphocyte death in vivo. J Exp Med 181: 1661-1672, 1995.

20. Reichard KW, Lorence RM, Cascino CJ, Peeples ME, et al: Newcastle disease virus selectively kills human tumor cells. J Surg Res 52: 448-453, 1992.

21. Csatary L, Eckhardt S, Bukosza I, Czegledi F, et al: Attenuated veterinary virus vaccine for the treatment of cancer. Cancer Detect Prev 17: 619-627, 1993.

22. Csatary LK and Bakács T: Use of Newcastle disease virus vaccine (MTH-68/H) in a patient with high-grade glioblastoma. JAMA 281: 1588-1589, 1999.

23. Schirrmacher V and Fournier P: Newcastle disease virus: A promising vector for viral therapy, immune therapy, and gene therapy of cancer. Methods Mol Biol 542: 565-605, 2009.

24. Fábián Z, Töröcsik B, Kiss K, Csatary LK, et al: Induction of apoptosis by a Newcastle disease virus vaccine (MTH68/H) in PC12 rat phaeochromocytoma cells. Anticancer Res 21: 125-135, 2001.

25. Washburn B, Weigand MA, Grosse-Wilde A, Janke M, et al: Tnf-related apoptosis-inducing ligand mediates tumoricidal activity of human monocytes stimulated by Newcastle disease virus. J Immunol 170: 1814-1821, 2003.

26. Elankumaran S, Rockemann D and Samal SK: Newcastle disease virus exerts oncolysis by both intrinsic and extrinsic caspase-dependent pathways of cell death. J Virol 80: 7522-7534, 2006.

27. Molouki A, Hsu YT, Jahanshiri F, Rosli R and Yusoff K: Newcastle disease virus infection promotes Bax redistribution to mitochondria and cell death in HeLa cells. Intervirology 53: 87-94, 2010.

28. CEC: Council Directive 92/66/EC of 14 July 1992 introducing community measures for the control of Newcastle disease. Off J Eur Comm L260: 1-20, 1992.

29. Ramanujam P, Tan W, Nathan S and Yusoff K: Novel peptides that inhibit the propagation of Newcastle disease virus. Arch Virol 147: 981-993, 2002.

30. Nicoletti I, Migliorati G, Pagliacci M, Grignani F and Riccardi C: A rapid and simple method for measuring thymocyte apoptosis by propidium iodide staining and flow cytometry. J Immunol Methods 139: 271-279, 1991.

31. Nagai Y, Hamaguchi M and Toyoda T: Molecular biology of Newcastle disease virus. Prog Vet Microbiol Immunol 5: 16-64, 1989.

32. Wilde A and Morrison T: Structural and functional characterization of Newcastle disease virus polycistronic RNA species. J Virol 51: 71-76, 1984.

33. Ravindra P, Tiwari AK, Ratta B, Chaturvedi U, et al: Newcastle disease virus-induced cytopathic effect in infected cells is caused by apoptosis. Virus Res 141: 13-20, 2009. 
34. Ravindra P, Tiwari AK, Ratta B, Chaturvedi U, Palia SK, Subudhi PK, Kumar R, Sharma B, Rai A and Chauhan R: Induction of apoptosis in Vero cells by Newcastle disease virus requires viral replication, de-novo protein synthesis and caspase activation. Virus Res 133: 285-290, 2008.

35. Tyler KL, Squier M, Rodgers SE, Schneider BE, et al: Differences in the capacity of reovirus strains to induce apoptosis are determined by the viral attachment protein sigma 1. J Virol 69 6972-6979, 1995.

36. Schirrmacher V, Haas C, Bonifer R and Ertel C: Virus potentiation of tumor vaccine $\mathrm{T}$-cell stimulatory capacity requires cell surface binding but not infection. Clin Cancer Res 3: 1135-1148, 1997.

37. Zeng J, Fournier P and Schirrmacher V: Induction of interferonalpha and tumor necrosis factor-related apoptosis-inducing ligand in human blood mononuclear cells by hemagglutininneuraminidase but not $\mathrm{F}$ protein of Newcastle disease virus. Virology 297: 19-30, 2002.

38. Jan JT and Griffin DE: Induction of apoptosis by sindbis virus occurs at cell entry and does not require virus replication. J Virol 73: 10296-10302, 1999.

39. Ramsey-Ewing A and Moss B: Apoptosis induced by a postbinding step of vaccinia virus entry into Chinese hamster ovary cells. Virology 242: 138-149, 1998.

40. Carrascosa AL, Bustos MJ, Nogal ML, González de Buitrago G and Revilla Y: Apoptosis induced in an early step of African swine fever virus entry into Vero cells does not require virus replication. Virology 294: 372-382, 2002.
41. Hightower LE and Bratt MA: Protein synthesis in Newcastle disease virus-infected chicken embryo cells. J Virol 13: 788-800, 1974.

42. Lam K and Vasconcelos A: Newcastle disease virus-induced apoptosis in chicken peripheral blood lymphocytes. Vet Immunol Immunopathol 44: 45-56, 1994.

43. Crompton M: The mitochondrial permeability transition pore and its role in cell death. Biochem J 341: 233-249, 1999.

44. Revillard JP, Adorini L, Goldman M, Kabelitz D and Waldmann H: Apoptosis: potential for disease therapies. Immunol Today 19: 291-293, 1998.

45. Thornberry NA and Lazebnik Y: Caspases: enemies within. Science 281: 1312-1316, 1998.

46. Ravindra P, Tiwari AK, Ratta B, Bais MV, et al: Time course of Newcastle disease virus-induced apoptotic pathways. Virus Res 144: 350-354, 2009.

47. Collins PL and Hightower LE: Newcastle disease virus stimulates the cellular accumulation of stress (heat shock) mRNAs and proteins. J Virol 44: 703-707, 1982.

48. Kasibhatla S, Brunner T, Genestier L, Echeverri F, et al: DNA damaging agents induce expression of Fas ligand and subsequent apoptosis in T lymphocytes via the activation of NF-kappa B and AP-1. Mol Cell 1: 543-551, 1998. 